\title{
Polysèmes
}

Revue d'études intertextuelles et intermédiales

Videogames' Specific Forms of Immersion into the Past, Present, and Future: Experiencing Progress in American McGee's Alice (2000) and Alice: Madness Returns (2011)

Immersion vidéoludique dans le passé, le présent et l'avenir : progrès, progression et expérimentation dans American McGee's Alice (2000) et Alice:

Madness Returns (2011)

\section{Clémence Folléa}

\section{CpenEdition}

\section{Journals}

Electronic version

URL: http://journals.openedition.org/polysemes/6446

DOI: 10.4000/polysemes. 6446

ISSN: 2496-4212

Publisher

SAIT

Electronic reference

Clémence Folléa, "Videogames' Specific Forms of Immersion into the Past, Present, and Future: Experiencing Progress in American McGee's Alice (2000) and Alice: Madness Returns (2011)", Polysèmes [Online], 23 | 2020, Online since 30 June 2020, connection on 02 July 2020. URL : http:// journals.openedition.org/polysemes/6446; DOI : https://doi.org/10.4000/polysemes.6446

This text was automatically generated on 2 July 2020.

Polysèmes 


\section{Videogames' Specific Forms of Immersion into the Past, Present, and Future: Experiencing Progress in American McGee's Alice (2000) and Alice: Madness Returns (2011)}

Immersion vidéoludique dans le passé, le présent et l'avenir : progrès, progression et expérimentation dans American McGee's Alice (2000) et Alice: Madness Returns (2011)

\section{Clémence Folléa}

Although American McGee's Alice (2000) and its sequel Alice: Madness Returns (2011) are openly adapted from Lewis Carroll's Alice books, ${ }^{1}$ they are "neo-Victorian" only in what Nadine Boehm-Schnitker and Susanne Gruss call a "soft" or "inclusive" sense (BoehmSchnitker and Gruss 2): in contrast with "strong" definitions, long predominant in academia, "which make self-reflexivity [...] a conditio sine qua non of the neo-Victorian reference to the nineteenth century" (Boehm-Schnitker and Gruss 2), neither of these games explicitly aims at challenging our conception of the past and the present by engaging us in self-reflexive and intellectually demanding representations. Rather, American McGee's Alice and Alice: Madness Returns rely on Victorian texts and tropes to create intensely "immersive" and "affective" experiences (Boehm-Schnitker and Gruss 3), likely to attract a broad audience. Thus, for instance, the two games contain a high level of gore and violence-which constituted an appealingly rare and controversial feature in 2000, and had, by the early 2010s, become an important selling point of many commercial action games. In both cases, the marketing campaigns designed by the publishing company, Electronic Arts, emphasised the games' horrific quality, promising the audience a viscerally thrilling plunge into nightmarish worlds. On the creative side, the developing teams were led by designer American McGee, who made it clear that he chose the Alice books as source material in order to exploit their 
"dark narrative pieces" (McGee 2018a, 33:30). ${ }^{2}$ And indeed, these adaptations are intensely sinister: the heroine is morbidly mad, several of Carroll's characters become ruthless foes, toys are used as weapons, and much of the Victorian-looking setting is spectacularly grim, filled as it is with hellish factories, dismal mental asylums, and hordes of maimed orphan children. The games present a Gothic-looking representation of Carroll's texts and their Victorian context, which therefore stand out as very much " other-than the present" (Gutleben and Kohlke 12, original emphasis) and serve to emphasise or inspire contemporary improvements-be them technological, sociocultural, or ethical. However, even as they support a firmly progressive and forwarddriving vision, these adaptations also provide other possible perspectives on progress. Indeed, as videogames, they offer several ways for the player to penetrate, exist in, and experience their fictional worlds: these different modalities of immersion-narrative, visual, interactive-make for a multi-layered experience, allowing us to embrace the heroine's mad vision in all its complexity and to apprehend the connections between past, present, and future in more ways than one.

\section{Narrative immersion: tales of progress}

American McGee's Alice and Alice: Madness Returns are story-driven games, which is to say that their narratives are designed to play a prominent role in the player's immersion. This is not the case of all videogames: with interactivity being the core specificity of this medium, plots are sometimes considered to play second fiddle in the play experience, while the focus is placed rather on systems of rules and other possible interactions with the game world. American McGee started his career in a developing company which was famous for producing such non-narrative games: as a young designer at id Software, he worked on first-person shooters like Doom (1993) and Quake (1996), where the user's attention is focused on immediate action rather than on narrative development. McGee recalls that the co-founder of id Software famously considered "story in videogames [to be] about as useful as story in pornography"-and he explains that his own experience in the company eventually gave him "an itch, a desire to build games with story" (McGee 2018a, 1:00:07). This is evident in his Alice games, which he developed soon after coming out of id Software. Indeed, these games adapt their source texts into a well-structured and compelling narrative, revolving around madness, depression, and the possibility to recover from traumas. ${ }^{3}$ In American McGee's Alice, we discover Carroll's heroine as a young woman who was traumatised by the death of her family in a fire, shortly after her adventures beyond Carroll's lookingglass. Alice, now suffering from hallucinations and violent fits, is considered mad and remains locked up in a mental hospital. There, she seeks escape by plunging into her inner world-a corrupted version of Wonderland and Looking-Glass World-where she must find and defeat the Queen of Hearts, an imaginary embodiment of her own guilt and depression. Alice eventually succeeds in doing so, which enables her to "reclaim her sanity" and abandon "the sterile safety of her self-delusions", as the Queen puts it during the game's final fight (American McGee's Alice). At the end of the game, Alice is seen leaving the asylum, while a Tenniel-like illustration in her open book shows a party of Carroll's smiling characters, along with the caption "happily ever after." However, Alice: Madness Returns re-opens the young heroine's dark story, with Alice having relapsed into madness one year after her release from the asylum. The young woman is now followed by a psychiatrist, Dr Angus Bumby, who uses hypnosis to make 
her forget her past. Throughout this game, Alice moves in and out between the real world of Victorian London and its imaginary transposition into her inner Wonderland, where an "Infernal Train" has now caused corruption. The player gradually realises that Dr Bumby is a fraud and a criminal, who uses hypnosis to turn young orphans into sex slaves and prostitutes, and who, in Wonderland, is the driver of the Infernal Train. At the end of this game, Alice defeats him in both imagination and reality. She then finally succeeds in reconciling with her past, rather than forgetting about it: the last sequence shows her walking into "Londerland", a hybrid world representing Alice's progression into "a fully-realised and whole person", as McGee explains (McGee 2011). Thus, the two Alice games offer compelling narrative experiences based on forwarddriving linear plots: in McGee's words, the player accompanies Alice on "her hero's journey [...] confronting the obstacle, acquiring the tools to fight the obstacle, fighting the obstacle, overcoming the obstacle, and then passing through to the other side and using the lessons you've learned to evolve yourself to the next level" (McGee 2017, 1:22:46). This sense of forward-driving evolution often emerges locally, in the guidance which the player receives throughout her progression. In American McGee's Alice for instance, the Cheshire Cat soon advises our avatar to "suppress [her] instinct to lead" and insists that "knowing where you are going is preferable to being lost" (American McGee's Alice). This remark, poles apart from the original Cheshire Cat's insistence that "it doesn't matter which way you go" (Carroll 1865, 75), makes it immediately clear that our narrative experience will be structured around one overarching linear path, from which there will be little straying. Injecting such narrative linearity into Carroll's original tales seems paradoxical, especially for an interactive adaptation. Indeed, whereas McGee judged the Alice books to be "good material for [...] games that [tell] a story" (McGee 2018a, 1:00:07), these novels are in fact extremely "episodic, disjointed, weakly plotted, picaresque in structure rather than strongly end-oriented" (McHale 57). Carroll's books explicitly frustrate the desire for plot, constantly denying Alice the coherent evolution and linear progression towards a resolution that she wishes for. ${ }^{4}$ As interactive fictions, story-driven videogames have the power to make such frustration even more palpable, for instance by building branching plots in which users' choices eventually turn out to matter very little, thus giving out a sense of narrative arbitrariness. However, while such choice-based fictions offer the possibility to create self-reflexive narrative experiences, where "the interest [...] lies in the multiplicity of paths, not in any particular development" (Ryan 20), they do not allow their users to immerse themselves in their stories. On the other hand, narrative immersion is precisely the prime purpose of many commercial adaptations of Alice: TV mini-series and Hollywood versions of Carroll's books often "narrativiz[e] Alice", by giving the heroine "something to do, [or] devising a mission for her to undertake" (McHale 58, original emphasis). Similarly, McGee wanted to integrate Alice into a "linear, story-driven very well-put-together experience" (McGee 2018b, 11:05) likely to attract and compel a large audience.

In the games, this gripping narrative experience revolves around the possibility for progress and productive change: in both American McGee's Alice and Alice: Madness Returns, the heroine must come to terms with her past so that she can fully live in the present and move on towards a brighter future. McGee explains that he designed these dark stories so that their resolution could be "cathartic" and "would help people deal with their traumas" (McGee 2017, 1:17:05). This effect is based on the transformation of Alice "from passive good girl to aggressively assertive action heroine" (Kerchy 116). 
Indeed, these adaptations drastically expand upon the discreet possibility for emancipation and rebellion underlying the original heroine's actions: whereas the books show little Alice unintentionally subverting Victorian lessons and rules, the games make her into a self-assumed, self-reliant, cheeky, and ultimately inspiring young woman. Although our avatar is the victim of guilt, violent fits, and hallucinations, she fights against her demons recklessly and moves forward persistently, eventually succeeding in overcoming her trauma and, in the second game, even defeating a real-life sexual predator, Dr Bumby. As a result, McGee's immersive tales of narrative progress also embody tales of socio-cultural progress, in the sense that they are governed by a progressive twenty-first century ideology: the story of Alice's psychological liberation also constitutes an "empowerment fantas[y]" (Siemann 180), which is typical of many recent commercial adaptations. Like Tim Burton's 2010 Alice in Wonderland for instance, McGee's games show the heroine liberating both herself and Wonderland from oppressors and predators. Such contemporary productions decidedly present the character as "un-Victorian" (Siemann 193) in her successful fight for independence, instead "portra[ying] an Alice infused with twenty-first-century ideology" (Manning 171) and offering the audience a progressive perspective on their source texts. Besides, in the context of the contemporary videogame industry, McGee's version of Alice as a strong and inspiring heroine stands out as particularly progressive. As is explained by Ken Wong, art director on Alice: Madness Returns, this female avatar differs from many others, in so far as she is "not framed in a relationship with a male, she's not the sidekick of a male, she's not a daughter, she's not the love interest. She's her own person" (Harris). Wong recalls, for instance, that the artists working on the game resolutely resisted the recommendations given by the developing company, Electronic Arts, that the team should make Alice "look a bit more like Angelina Jolie" (Harris 2013). The representation of Alice as a strong and ultimately self-reliant young woman is therefore doubly progressive, since it allows the heroine both to move away from the conservative models of femalehood governing nineteenth-century culture and to resist those still persisting in the present. Thus, in McGee's games, the possibility for productive change applies not only to Alice's intra-diegetic narrative, but also to her extra-diegetic socio-cultural progression as a female character. In this context, the Victorian past represents a darker state of society and culture, which can be dealt with and left behind just like the traumas of Alice's childhood. ${ }^{5}$ This vision of the past is especially evident in the game's steampunk aesthetics, ${ }^{6}$ which are prominently reserved for enemies and hostile environments: each game features at least one level where Victorian-looking industrial technologies are put to terrifying uses. In American McGee's Alice, a level called "Crazed Clockwork" shows the Mad Hatter conducting "cruel experiments [...] with gears, springs, levers and mechanical gizzards" (American McGee's Alice), and employing them to torture the Dormouse and the March Hare. The end of this level features a monstrous Jabberwocky, appended with mechanical wings strapped to a small furnace and set of gears on his chest-a genuine steampunk monster. In Alice: Madness Returns, the Mad Hatter becomes the head of an entire factory, which makes for a hellish level filled with torrents of fire, steam vents, moving gears, and stomping presses. Alice's mission there is to collect the Hatter's limbs, recently torn out and hidden by the revengeful Dormouse and March Hare. This connection between Victorian industrial technologies and utmost violence is also borne out by the Infernal Train which wreaks havoc through Wonderland in the sequel. The 
train is a hellish machine and an assault on the senses, as the Hatter explains to Alice: "This railroad's a bloody shambles. The stink is ferocious, light blinding, the noise hellacious!" (Alice: Madness Returns). Victorian industrial technologies thus appear as predominantly "de-naturing", since the games' steampunk aesthetics emphasises their "Gothic dark side" (Gutleben and Kohlke 21). Interestingly, this grim representation of dangerous technologies remains confined to Victorian innovations and is never associated to contemporary scientific progress: unlike many steampunk fictions, the games never "call the orthodox idea of progress into question" or openly warn us about "the consequences of [...] an untempered drive to mastery" (Rose 328 and 330). Rather, Victorian industrial technologies are here integrated into another tale of progress, celebrating the contemporary digital technologies which allowed for the creation of such terrifyingly immersive steampunk environments.

\section{Visual immersion: a celebration of technological innovation}

4 Like many twenty-first-century commercial games, American McGee's Alice and Alice: Madness Returns rely heavily on their spectacular graphics in order to offer an intensely immersive experience. Indeed, since the late 1990s, the game industry has sought to emulate film by creating more and more impressive visuals, which are displayed especially in so-called "cutscenes" or "cinematics". These non-interactive sequences, which temporarily pause the play experience in order to introduce or advance the narrative, are produced by powerful computer engines able to render high-quality animations. The videogames which integrate such sequences openly remediate cinema, using film-like images and codes in order to maximise their appeal as innovative and thrilling visual productions. Thus, like many contemporary games, American McGee's Alice starts with a cinematic, which launches immediately after the player clicks on "New Game" in the main menu. Here, a two-minute animation shows how the heroine, as a child, witnessed the death of her parents in a fire and ended up in mental hospital. The frame moves erratically from Alice's face to objects surrounding her, giving us to understand that she was asleep when her cat knocked a candle and set a fire of which the girl was the only survivor. After this, a series of abrupt cuts show Alice as a young woman resting on an iron bed and then plunging into her inner Wonderland, which is symbolised by a long and erratic fall down a hole. This opening cinematic sequence therefore resorts to codes of horror films, telling its story through a series of disjointed and unsteady close-ups which evoke the disturbing quality of Alice's memory. Besides, the animation is interrupted at irregular intervals by shots of still images, such as Tenniel-like illustrations or black-and-white photographs. This unsteady back-and-forth movement between still and moving images emphasises the disturbance and alienation felt by the heroine when remembering the fire: since the representation is never predictably set upon one medium, our immersion into the game's fiction is as unstable as Alice's grasp of reality. By using such a "techniqu[e] of intermediality" (Kerchy 117) at its opening, the game thus immediately invites us to empathise with Alice's distorted vision of the world. In fact, both American McGee's Alice and Alice: Madness Returns continuously offer a sympathetic perspective on madness, which is as carefully-designed as their female avatar, contrasting with the simplistic representations prominent in videogames until very recently. But while the disturbing 
and unstable quality of the game's cinematic opening certainly invites players to immediately empathise with Alice's troubled perception, it also serves another equally important function: at the threshold of a 2000 game, the introduction of Victorian illustrations and black-and-white photographs into the animation dramatically highlights the technological achievement which this animated sequence represents. As McGee himself recently explained, this opening cutscene was first and foremost designed to look "impressive" for a contemporary audience, whose eye was to be caught by its "CGI-resolution, [...] a very high-quality thing in comparison to a lot of the videos that were getting made [at that time]" (McGee 2018a, 10:31). Such a statement is symptomatic of the game industry's determination to emulate cinema thanks to increasingly sophisticated digital tools: the high-quality sequence at the beginning of American McGee's Alice functions as an eye catcher, signalling that the game "was really pushing [...] what people's expectations were of games in general at this time in history" (McGee 2018a, 29:00) and explicitly celebrating its own use of cutting-edge technology to create a visually immersive experience.

5 Such forward-looking representations are typical of contemporary commercial videogames, which often "presen[t] [themselves] to [their] potential players through a rhetoric of future possibility, whether that be focused on shader and lighting effects, [or] new and previously unseen spectacle" (Atkins 140). As is heralded by the opening sequence of the first Alice game, McGee's productions provide radically new versions of their Victorian source texts, using the most innovative of contemporary technologies in order to create an unprecedented, almost futuristic experience of visual immersion. The irruption of Victorian book illustrations and black-and-white photographs into the flowing animation are heavy with suggestions of an "intermedial revenge of the New World/Media upon the Old" (Kerchy 117): at its very threshold, the game gestures towards the technological evolution that resulted in its own spectacular digital representation. Such celebratory emphasis on technological progress is in fact recurrent in the game, and emerges for instance in the Save/Load screen. There, the player can access and reload her progression where she stopped and saved it. Each save is represented by a black-and-white screenshot displayed on a monitor branded "Bandersnatch Opticals", which resembles a camera obscura, a graphoscope, or some other piece of nineteenth-century visual technology. These screenshots appear on the monitor "whirring and flickering like early cinema" (Brooker 234). When the player clicks upon one of the images, it returns to full screen and "full motion colour", so that "the process imaginatively represents a shift in technology from Carroll's form of photography through silent film to contemporary cinema, or CGI" (Brooker 234). Again, just as the player moves into the game, the game reminds her of how it itself has moved away from the past in order to provide such an immersive version of its Victorian source texts. In this, McGee's 2000 Alice closely resembles Burton's 2010 filmic adaptation, which also

[...] enacts a symbolic representation of technological change as it moves from the traditional cinematography used to depict the opening scene of a rigid, austere, almost stagnant, nineteenth-century garden party to the sophisticated, hybridised techniques employed in the creation of a dynamic, vibrant, and three-dimensional Wonderland, into which the viewer feels plunged along with Alice. (Manning 173)

6 In Burton's version of Alice, as in McGee's, the Victorian past is associated with a dated state of visual technology which, by contrast, brings out the almost futuristic quality of these new representations. In American McGee's Alice, nineteenth-century visual 
technologies represent a point of comparison or a point of departure which the player moves away from in order to penetrate into a more spectacular and immersive version of Wonderland and Looking-Glass World. Here again, McGee's adaptation is poles apart from Carroll's novels, which implicitly link new visual technologies to anxieties about our possibly unstable perception of the world. ${ }^{7}$ In the videogame versions of Alice, innovative visual technologies explicitly allow us to access and empathise with troubled perceptions of the world, and therefore to better comprehend them. Digital tools helped McGee to create his "well-put-together experience" (McGee 2018b, 11:05) and thus to engage a wide audience in Alice's demented perception and in the story of her self-liberation. However, our immersion into Alice's distressed and struggling mind relies not only on linear tales of narrative and technological progress, inexorably moving towards resolution and improvement. Indeed, these adaptations also invite their audience to participate in a much less linear and more directly perturbed experience of progress, which emerges thanks to the medium's interactive quality.

\section{Interactive immersion: a gameplay of disrupted progression}

Although American McGee's Alice and Alice: Madness Returns feature many spectacular cinematics, these do not constitute the essential features of the play experience. Indeed, the film-like images displayed in cutscenes pause the games' interactivity, thus temporarily transforming the player into a spectator. But, for the better part of the Alice games, the user's relation to images is based on interaction rather than merely on observation: during gameplay sequences, the player must lay her hands on the controller and steer Alice through the game's 3D environments, choosing how to negotiate the path open before her. Thus, outside of cinematics, each image offers a "possible future of a vast array of potential images [which] is accessible only to the player and not to the spectator. We must do much more than simply observe" (Atkins 139). In American McGee's Alice and Alice: Madness Returns, progress is not only something we follow in the narrative or admire in the visuals-it is also something we must accomplish ourselves. Although, as the Cheshire Cat intimates at the beginning of American McGee's Alice, we must follow a linear path and "suppress our instinct to lead" in the development of the overarching narrative, each step of the way implies that we make a series of micro-choices and conduct successful performances. Indeed, in order to steer Alice forward, we must perform actions whose nature is determined by the games' genres: American McGee's Alice and Alice: Madness Returns are hybrids of the 3D platformer and the third-person shooter, which both entail different gameplay mechanisms, that is to say different ways for the player to interact with the games' worlds. As platformers, like Mario or Rayman for instance, the Alice games imply that we perform tricky jumps from one platform to another, with the gradual addition of more and more difficult features, like slippery surfaces, invisible grounds, or moving obstacles. In the aforementioned factory levels, for instance, Alice must jump from one giant moving gear to another, while avoiding stomping machines and cascades of liquid fire. Besides, as shooters, these games face the player with hordes of enemies which must either be eluded or fought using the appropriate weapon. For instance, in American McGee's Alice, the player would be well-advised to select the slow but efficient "croquet mallet" for one-on-one melee combat but should swiftly switch to the fast- 
shooting "pack of cards" to deal with multiple attackers coming from a distance. Although the toy-like design of Alice's weapons is inspired by Carroll's books, which were initially destined for children, their mechanics match those of the formulaic shooter arsenal, with the pack of cards resembling the traditional machine-gun for instance. These versions of Alice therefore offer a type of immersion that is truly specific to their genre and more broadly to their medium: while the player might be gripped by the development of the games' forward-driving narratives or absorbed by their futuristic-looking visuals, the better part of her immersive experience centres around her interaction with the gameworld, that is to say the performance of actions to advance on the path open before her. At every stage of her progression, the player must choose whether to shoot, run, or jump, and must conduct these actions successfully by pressing buttons on her keyboard or controller, with great eye-hand coordination.

8 This results in an immersive posture which is more complex than that of even the most spectacular film adaptations, for "not only are we able to see and feel, we are even able to ACT upon what we see in light of our concerns, our (inter)active motor capabilities allows us to so shoot at what frightens us or approach what activates our curiosity" (Grodal 132). In the videogame versions of Alice, we perceive the meaning and materiality of progress not only through visual and oral provocations, but also through our kinaesthetic implication: here, progress is a concrete experience whose realisation rests on bodily implication and response. As action games, American McGee's Alice and Alice: Madness Returns make sure that the player "always apprehends the game as a matrix of future possibility" (Atkins 137) not only in narrative or technological terms: these adaptations of Alice "prioritize the participation of the player as he or she plays" (Atkins 137), demanding kinaesthetic involvement and action, and therefore creating a more complete form of engagement. Thus, the games provide intensely immersive experiences not only through their gripping narrative and enthralling visuals, but even more importantly through their interactivity. In this respect, the transformation of the Alice books into a series of videogames participates in and dramatizes the "move within neo-Victorianism [...] to capitalise on intense somatic sensations and affect" (Gutleben and Kohlke 2012, 16). In McGee's versions of Carroll's books, Wonderland is not only a sensational 3D spectacle, as in Burton's film, but also constitutes an interactive environment which cannot evolve or unfold without the user's participation. Similarly, Alice is not only a strong and inspiring heroine accomplishing a thrilling mission, but also an avatar whose progression must be driven by the player. With these adaptations, our bodily response does not only include heart palpitations at the sight of the monstrous Jabberwocky, tears upon the death of the White Rabbit, or laughter at one of Alice's cheeky quips, but also intent eye movements in quest of interactive content, and swift finger movements on the controller in reaction to provocations displayed on the screen: as the player participates in the unfolding of the avatar's progression, her immersion becomes more intense. Interestingly, our very participation in the games' tales and spectacles of progress results in a disruption of their linearity. Indeed, although American McGee's Alice and Alice: Madness Returns are structured around overarching narratives which are entirely scripted and linear, the player's actual experience is not one of smooth or predictable linearity. Indeed, whereas the player must successfully perform actions to advance in the gameworld and in the narrative, she is very often unsuccessful in her performance, and must go through many cycles of dying and retrying before moving on to the next stage of her progression: when the 
player misses a jump or fails to defeat an enemy, the avatar dies and the game is resumed at the point where it was last saved. American McGee's Alice, like many action games, even includes a specific feature which anticipates upon this experience of perturbed progression: a key on the controller is assigned to a "quick save" function, which allows the player to save her progression without the trouble of going through the menu and therefore enables her to do so often, in anticipation of the many times when her linear progression will be interrupted by failure. Thus, while our immersion in these games is underlain by linear and forward-driving tales of progress, these can unfold only through a succession of trial, error and repetition, so that "[a] reconstruction of all the time used on the game would yield a giant tree with numerous forks (the save games), numerous dead ends, and only one path through" (Juul 138). As a result our very participation in the unfolding of the games' progression perturbs the linearity that structures our narrative and visual immersion: the play experience is one of confusion, unexpected interruptions, and disrupted progression, much like what Alice goes through in Carroll's original texts.

In particular, these games make the most of their generic features as platformers in order to create a sense of instability and uncertainty. Indeed, each level comes with a new amount of disorientating features, such as invisible platforms appearing only when we look into a mirror, mazes filled with fake doors, or environments that change shape as Alice walks through them. Although the player's ultimate aim is to master the games' logic and to achieve a successful progression, the heart of her experience has more to do with unpredictability and confusion than with mastery. Indeed, a videogame loses its interest once its logic is understood and its challenging mechanics are domesticated: when "[t]he virtual world becomes predictable, [...] the player will probably stop playing the game at this stage" (Grodal 148). Thus, in spite of their gripping narratives and spectacular visuals, the Alice games make for a mitigated and possibly disappointing experience once their mechanics are mastered: as a reviewer of Alice: Madness Returns explains, despite the game's enthralling "visual variety", it turns into little more than "a formulaic, flair-free jumping and fighting game" (Meer 2011) once its interactive challenges are overcome. Like many action games, American McGee's Alice and Alice: Madness Returns endeavour to prolong their players' implication by offering different levels of difficulty, to match the level of their skills: if playing the game in "easy" or "medium" mode proves unchallenging, the user can select the "hard" or even "nightmare" mode to ensure that failure, disorientation, and uncertainty remain part of her experience. Thus, whereas these games do not reproduce Carroll's disrupted linearity in their narratives, they do so in their gameplay, since their interactive challenges entail interruptions, repetitions, and a general sense of unpredictability: here, these videogame adaptations adopt what designer Ian Bogost calls the "Proceduralist Style", that is to say the "attempt to translate an author's idea into a ludic mechanic" (Flanagan 448). What is more, the games also feature perturbing elements that were not intended by the designers. Like many contemporary commercial games, despite the use of cutting-edge technology, American McGee's Alice and Alice: Madness Returns still contain errors, inconsistencies, and glitches. Reviewers have complained for instance about the uneven physics governing Alice's movements, about unpredictable slides due to the hazy contours of landing platforms, or about invisible walls preventing the avatar from reaching seemingly accessible areas. Such experiences are, as one reviewer puts it, further "opportunities for frustration and mistakes that feel beyond the player's control" (Bedford 2010). Although these features 
are not part of the intended design, they affect our immersion heavily, making our progression even more difficult and less predictable. The games' glitches, along with their gameplay challenges, thus create feelings of uncertainty and disorientation which prevent a linear experience of progress. Whereas the games' narratives and visuals use the past to imagine an inspiring progression towards a brighter, more liberated, and more technological future, their gameplay exploits the interactive specificity of their medium to disrupt this sense of linearity. With this participatory immersion into Alice, "[o]ur memory of the past always conditions how we anticipate the future, but that future is both predictable and unpredictable, always potential and unknowable until brought into being by the action of playing" (Atkins 139). As a result, these adaptations allow their users to safely experience the confusion and disorientation which Alice goes through in Carroll's books: against the comfortable background of the games' forwarddriving narratives, progressive ideology, and innovative visuals, the player can also access a much less linear and more perturbed experience of progress.

\section{Conclusion: immersion and participation}

Although they are neo-Victorian only in a "soft" sense (Boehm-Schnitker and Gruss 2), these immersive adaptations of Carroll's Alice allow for a richly multi-layered, sometimes contradictory experience of progress and of the relationship between past, present, and future. On the one hand, American McGee's Alice and Alice: Madness Returns rely on narrative and visual immersion in order to support a firmly progressive view, based on linear and forward-driving aesthetics: the games repeatedly use Victorian texts and tropes to celebrate the possibilities offered by their contemporary medium and context, and to inspire further improvements. With their spectacular graphics and their gripping narratives, American McGee's Alice and Alice: Madness Returns have thus been able to entice a relatively wide audience of gamers into adopting fairly radical perspectives, concerning for instance the representation of female avatars or that of madness in videogames. On the other hand, the games' decidedly linear, and forwarddriving principles also cohabit with a much more disrupted experience of progress, which emerges from our interactive immersion. Indeed, while the player is constantly invited to look and advance towards a brighter future-be it that of narrative resolution, technological innovation, or socio-cultural improvement-her interactive experience is inherently structured by "an aesthetics of repetition" (Grodal 148, original emphasis). Whereas the cycles of failing and retrying imposed by the gameplay do not immediately transform the representation of Carroll's texts and their Victorian context, they radically affect our experience of them. As the player repeatedly tries, fails, and tires again to perform gameplay challenges, she develops a more perturbed sense of the relationship between past, present, and future: after having played for some time, the user becomes aware that her progression so far has been the result of chaotic experimentations and she anticipates that her forthcoming progress in the game will be equally chaotic. Thus, our experience of progress in American McGee's Alice and Alice: Madness Returns is structured simultaneously by a strong sense of linearity, derived from narrative and visual immersion, and by one of uncertainty and unpredictability, which leads us to question and experiment with causalities instead of taking them for granted and blindly trusting in forward-driving and linear paths. This interactive facet of immersion, which is specific to this medium, invites the audience to actively engage in, appropriate, and question the games' representations and their 
structuring principles. As a result, immersion becomes a form of participation, which, as Rosa Karl puts it, allows a wide audience to indulge in the fantasy that they can "possess a revised version of history and/or literature via a narration that transforms it into personal experience" (Boehm-Schnitker and Gruss 47). ${ }^{8}$ Although American McGee's Alice and Alice: Madness Returns achieved only relative commercial success when they came out, they have become cult classics and are now at the centre of a rather broad community of dedicated fans. On forums, blogs, and social networks, but also in art or cosplay events, videogame users thus prolong their active immersion into these contemporary versions of Alice, continuously creating new stories, images, and interactions based on McGee's adaptations, and therefore shaping the contemporary progress of Carroll's Victorian novels.

\section{BIBLIOGRAPHY}

Atkins, Barry. "What Are We Really Looking at? The Future-Orientation of Video Game Play". Games and Culture 1.2 (2006): 127-140.

Bedford, John. “Retrospective: American McGee's Alice”. Eurogamer, September, 26 2010. https:// www.eurogamer.net/articles/2010-09-26-retrospective-american-mcgees-alice-article, last accessed 30 December 2019.

Boehm-Schnitker, Nadine, and Susanne Gruss (eds.). Neo-Victorian Literature and Culture: Immersions and Revisitations. New York: Routledge, 2014.

Brooker, Will. Alice's Adventures: Lewis Carroll in Popular Culture. New York: Continuum, 2004.

Carroll, Lewis. Alice's Adventures in Wonderland (1865). London: Penguin, 1994.

Carroll, Lewis. Through the Looking Glass (1872). London: Penguin, 1994.

Elliott, Kamilla. “Adaptation as Compendium: Tim Burton's Alice in Wonderland”. Adaptation 3.2 (2010): 193-201.

Farrell, Jennifer Kelso. "Psychology is Technology: A Steampunk Reading of Alice: Madness Returns ". Foundation. The International Review of Science Fiction 44, no. 120.42 (2015): 42-51.

Flanagan, Kevin. "Videogame Adaptation". In The Oxford Handbook of Adaptation Studies, edited by Thomas Leitch, 441-55. Oxford: Oxford UP, 2017.

Grodal, Torben. "Stories for Eye, Ear, and Muscles: Video Games, Media, and Embodied Experiences". The Video Game Theory Reader. Mark J. P. Wolf, and Bernard Perron (eds.). New York: Routledge, 2003. 129-155.

Gutleben Christian, and Marie-Luise Kohlke (eds.). Neo-Victorian Gothic. Horror, Violence and Degeneration in the Re-Imagined Nineteenth Century. Amsterdam/New York: Rodopi, 2012.

Harris, Duncan. "Little China Doll: How Spicy Horse Imagined Alice: Madness Returns". RPS, December, 18 2013. https://www.rockpapershotgun.com/2013/12/18/little-china-doll-howshiny-horse-imagined-alice-madness-returns/\#more-181253, last accessed 30 December 2019. 
Juul, Jasper. "Introduction to Game Time”. First Person. New Media as Story, Performance, and Game. Noah Wardrip-Fruin, and Pat Harrigan (eds.). Cambridge, Massachusetts: MIT Press, 2004. 131-142.

Kerchy, Anna. Alice in Transmedia Wonderland: Curiouser and Curiouser New Forms of a Children's Classic. Jefferson, N. C.: McFarland \& Co, 2016.

Manning, Kara M. “'That's the Effect of Living Backwards': Technological Change, Lewis Carroll's Alice Books, and Tim Burton's Alice in Wonderland". Neo-Victorian Studies 4.2 (2011): 154-179.

McGee, American. 2011. "Re: What was the final fate of Alice in Madness Returns? *WILL CONTAIN SPOILERS* - Reply \#1”. Post on the forum of American McGee's blog, October, 172011. https://web.archive.org/web/20151101014930/http://www.americanmcgee.com/forum/ index.php?topic=3656.0, last accessed 30 December 2019.

McGee, American. 2017. “American McGee plays Alice: Madness Returns”. YouTube video, 1:58:03. Streamed live August, 10 2017. https://www.youtube.com/watch?v=DzpOjbnOxRc, last accessed 12 March 2020.

McGee, American. “Let's Play ‘American McGee’s Alice’ with American McGee!!!” YouTube video, 1:54:12. Streamed live March, 222018 (2018a). https://www.youtube.com/watch?v=nZS-

q_sxMM8, last accessed 12 March 2020.

McGee, American. "Alice: Tweedles in the Asylum - Flee and RUN!" YouTube video, 2:06:03. Streamed live June, 72018 (2018b). https://www.youtube.com/watch?v=vWMcCQOEQfE, last accessed 12 March 2020.

McHale, Brian. “Alice." The Cambridge Introduction to Postmodernism. Cambridge: Cambridge UP, 2015. 50-61.

Meer, Alec. 2011. “Wot I Think-Alice: Madness Returns”. Rock, Paper, Shotgun, June 202011. https://www.rockpapershotgun.com/2011/06/20/wot-i-think-alice-madness-returns/, last accessed 12 March 2020.

Ryan, Marie-Laure. Narrative as Virtual Reality: Immersion and Interactivity in Literature and Electronic Media. Baltimore: The Johns Hopkins UP, 2001.

Siemann, Catherine. “'But I'm grown up now': Alice in the Twenty-First Century”. Neo-Victorian Studies 5.1 (2012): 175-201.

$\mathrm{Yu}$, Mimi Dee. "Is it Mad to Pray for Better Hallucinations? From Carroll to McGee; from Children's Novel to Horror Action-Adventure Video Game". Master of Arts Thesis, U of Virginia, 2017.

\section{NOTES}

1. The Alice books have spawned a few videogames, none of which have achieved the long-lasting critical success that McGee's versions did. Several of these games are in fact by-products of Disney's film adaptations, with for instance a 2000 platform game based on the 1951 animated movie, or an action-adventure game derived from Tim Burton's 2010 Alice and released on the same week as the film.

2. While McGee considers that the original Alice books could be read by both adults and children (see $\mathrm{Yu}$ ), he designed his games specifically for a young-adult and adult audience. Part of his endeavour was to make the heroine older, as is the case in many recent "dark" versions of Alice. 
This trend is examined by Catherine Siemann in her article “'But I'm grown up now': Alice in the Twenty-First Century" (Siemann).

3. The games' rich representation of madness will only be addressed passingly in this article. For a more thorough examination, see $\mathrm{Yu}$.

4. For an analysis of the non-linear "game-like" structure of the original Alice narratives see Souvik Mukherjee, Video Games and Storytelling. Reading Games and Playing Books. Basingstoke: Palgrave Macmillan, 2015, 91-98.

5. For an examination of the use of trauma in the Alice games, see Christina Fawcett, "American McGee's Alice: Madness Returns and Traumatic Memory", The Journal of Popular Culture 49.3 (2016): 492-521. For an extended analysis of this trope in neo-Victorian fiction, see Kohlke, Marie-Luise, and Christian Gutleben (eds.), Neo-Victorian Tropes of Trauma. The Politics of Bearing After-Witness to Nineteenth-Century Suffering, New York: Rodopi, 2010. See also Susanne Gruss's chapter, "Spectres of the Past: Reading the Phantom of Family Trauma in Neo-Victorian Fiction" in BoehmSchnitker and Gruss.

6. The steampunk genre often underlies the use of neo-Victorian aesthetics in games, as is visible for instance in Bethesda's 2012 and 2016 Dishonored games, with their industrial environment running on whale oil, or in the 2014 interactive story 80 Days, which rewrites Phileas Fogg's journey filling it with mechanized camels, moving cities, and other such fantastic pieces of technology. But Neo-Victorian games also exist outside of this genre, with for instance Ubisoft's 2015 Assassin's Creed Syndicate and its nineteenth-century-London setting, along with manyalthough not countless-others.

7. For a fully-fledged exploration of Carroll's anxiety about visual technologies, see Manning 2011.

8. Rosa Karl's chapter, entitled "Participatory Desires: On Metalepsis, Immersion, and the RePlotting of the Victorian", argues for a more expanded view of popular interactions with cultural heritage, examining for instance Jasper Fforde's The Eyre Affair, sites and practices of heritage tourism, or participatory fan culture (Boehm-Schnitker and Gruss 38-50).

\section{ABSTRACTS}

By examining two videogame adaptations of Lewis Carroll's Alice books, this article seeks to look further into the "immersive practices" which, though deprived of the "self-reflexivity" traditionally associated with neo-Victorianism, constitute an important part of contemporary Victoriana (Boehm-Schnitker and Gruss 7 and 2). As videogames, American McGee's Alice and Alice: Madness Returns offer various forms of immersion-narrative, visual, and interactive-allowing their broad audience to adopt multiple perspectives on Carroll's texts and on their Victorian context. In many ways, these Gothic-looking adaptations depict the past as "other-than the present" (Gutleben and Kohlke 12, original emphasis), steadily celebrating progress and change. Their gripping forward-driving narratives invite users to resolve Alice's traumas, but also more generally to adopt a progressive perspective in which the Victorian is associated with a dark state of things, highlighting or inspiring contemporary improvements. These tales of progress and productive change are accompanied by a celebration of the technological innovations which allowed for the player's intense visual immersion: in American McGee's Alice in particular, the spectacular use of cutting-edge computer-generated imagery is often emphasized, especially through a contrast with Victorian visual technologies. But simultaneously, the games' linear tales 
of narrative and technological progress are perturbed by the very interactivity that defines their medium: the player's progression in the games' plots and spectacles always depends upon the completion of gameplay challenges which, however, are rarely overcome in the first attempt; thus, as the player goes through cycles of failure, repetition, and experimentation, her experience becomes one of participatory and disrupted progression.

Cet article propose d'analyser deux adaptations vidéoludiques des Alice de Lewis Carroll, afin d'interroger à nouveaux frais les "pratiques immersives" qui, bien que privées de la "réflexivité" habituellement associée au néo-victorien, constituent une part importante des victorianas contemporaines (Boehm-Schnitker et Gruss, 7 et 2, ma traduction). American McGee's Alice (2000) et Alice: Madness Returns (2011) sont des jeux vidéo, et proposent par conséquent plusieurs types de modalités immersives : grâce à leur univers à la fois narratif, visuel, et interactif, ces deux adaptations offrent à leur large public des perspectives multiples sur les textes de Carroll et sur leur contexte victorien. Par bien des aspects, ces adaptations aux allures gothiques font du passé victorien "l'autre du présent" (Gutleben et Kohlke, ma traduction), en célébrant explicitement les notions de progrès et de changement. Tout d'abord, ces jeux nous plongent dans une progression narrative téléologique, nous invitant à résoudre les traumatismes d'Alice mais aussi plus largement à adopter une perspective progressiste, dans laquelle le passé victorien apparaît comme un univers sombre et où le présent se dessine, par contraste, comme une source d'améliorations. En outre, les notions de progrès et de changement productif sous-tendent non seulement la structure narrative du jeu mais aussi son univers visuel, dont la qualité résolument immersive est célébrée et est clairement associée à des innovations technologiques de pointe : dans American McGee's Alice en particulier, la qualité des animations, spectaculaires pour l'époque, est mise en avant grâce à une série de contrastes explicites avec des technologies visuelles du $\mathrm{XIX}^{\mathrm{e}}$ siècle. Cependant, la structure linéaire, téléologique et progressiste des jeux est perturbée par une troisième modalité immersive, qui fait la spécificité médiatique de ces adaptations. En effet, pour avancer dans l'univers narratif et visuel des jeux Alice, le joueur doit se confronter à des séquences de gameplay qui donnent rarement lieu à une progression linéaire : tandis que le joueur essaye, échoue, recommence, et ne cesse d'expérimenter encore et encore avec l'univers interactif $\mathrm{du} \mathrm{jeu}$, son expérience $\mathrm{du}$ progrès devient participative, et se trouve ainsi constamment malmenée par ses propres efforts de progression.

\section{INDEX}

oeuvrecitee Alice's Adventures in Wonderland (book, 1865), Alice in Wonderland (film, 2010), Alice: Madness Returns (game, 2011), American McGee's Alice (game, 2000), Doom (game, 1993), Quake (game, 1996), Through the Looking Glass (book, 1872)

Keywords: neo-Victorian, adaptation, videogame, immersion, interactivity, progress, linearity Mots-clés: néo-victorien, adaptation, jeu vidéo, immersion, interactivité, progrès, linéarité

\section{AUTHORS}

\section{CLÉMENCE FOLLÉA}

Clémence Folléa (LARCA UMR 8225, CNRS, Université de Paris) is an Associate Professor at Paris Diderot University, where she teaches literature, film, and videogame studies in the English department. In her research, she looks at new media and contemporary cultural practices through the prism of cultural persistence, studying for instance various phenomena of adaptation. She wrote her PhD on the afterlives of Charles Dickens's work and has published 
several articles and chapters on the subject, such as "Normative Ideology, Transgressive Aesthetics: Depicting and Exploring the Urban Underworld in Oliver Twist, Twist (2003) and Boy Called Twist (2004)" (Cahiers Victoriens et Édouardiens, 2014) or "Crossing Thresholds: The Aesthetics of an Urban Experience, from Oliver Twist to The Wire" (Unsettling Dickens: Process, Progress and Change, 2016). 